of foods to be included to cover nutritional requirements in Day Nurseries, Children's Homes, etc. and reports include those for the Mobile Meals Service, Old People's Homes and a small survey concerning children's breakfasts and what they ate at mid-morning break.

Guidance on nutritional matters is given to people, both trained and in-training, such as doctors, health visitors, social workers, home nurses, home helps and midwives working in the field of health or welfare who can play a significant part in spreading a greater knowledge of nutrition among the community. The Medical Officer of Health for Bristol is also Professor of Public Health at the University of Bristol and many courses are arranged jointly by the Department and the University.

Food and health are intimately related. Modern research is still bringing to light hitherto unknown and unexpected relationships. It has been said, 'People do not eat what they like, they like what they eat traditionally and each group has to teach its children in detail, how to like the particular foods on which they depend for sustenance'.

It is hoped that this account gives some idea of how a dietitian working in a Department of Public Health may further this.

\title{
REFERENCES
}

Brockington, C. F. (1946). Proc. Nutr. Soc. 4, 278.

Browe, J. H. (1959). In Preventive Medicine. [H. E. Hilleboe and G. W. Larimore, editors.] Philadelphia and London: W. B. Saunders.

Kemp, R. (1967). Medical News Magazine, January, p. 2.

Reid, J. J. A. (I g66). Nutrition, Lond. 20, 144.

Sinclair, H. M. ( (1965). Conf. Pap. R. Inst. publ. Hlth Hyg.

'Taylor, G. F. (1967). Medical Nezws Magazine, January, p. 10.

\section{An approach to the treatment of the obese schoolchild}

\section{By Phyldis M. Mortimer, Physician in charge of Weight Control Clinic, Public Health Department, Croydon}

There can be few medical topics that have received so much publicity in recent years as obesity and its treatment. Programmes have been devoted to the subject on radio and television, and women's magazines are constantly producing pages of helpful advice for the would-be slimmer.

With all this attention focused on a condition whose treatment (and serious consequences if left untreated) is well-known, an improvement in the incidence might have been predicted. Unfortunately, the converse is true and the percentage of overweight people in the populations of the USA and Great Britain is steadily rising. At present this is most clearly shown among adults but the increase in obesity in schoolchildren is considerable. In one secondary girls' school in Croydon an analysis of the heights and weights of the pupils in 1965 showed that, compared with Scott's (1955) figures for the London County Council in 1954 there was an increase of $5.9 \%-15.6 \%$ in mean weight, but only $1.98 \%-3.02 \%$ increase in mean height as shown by Table $\mathrm{I}$. 
Table I. Heights and weights of girls in one Croydon School, 1965

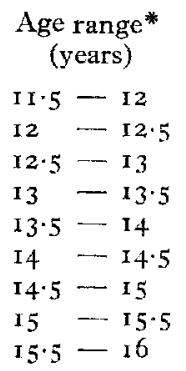

\begin{tabular}{lc}
\multicolumn{2}{c}{ Height (in.) } \\
Mean & SD \\
58.36 & $2 \cdot 692$ \\
$59 \cdot 2$ & $3 \cdot 341$ \\
61.43 & $2 \cdot 877$ \\
61.90 & $2 \cdot 430$ \\
63.42 & 2.887 \\
63.54 & $2 \cdot 468$ \\
63.58 & $2 \cdot 475$ \\
64.29 & 2.588 \\
64.88 & 2.050
\end{tabular}

\begin{tabular}{cc}
\multicolumn{2}{c}{ Weight (lb) } \\
Mean & SD \\
90.73 & 17.66 \\
94.33 & 20.53 \\
103.34 & 18.09 \\
$107.01 \dagger$ & 18.90 \\
114.87 & 21.69 \\
121.36 & 25.19 \\
120.57 & 17.17 \\
120.72 & 13.31 \\
123.68 & 19.51
\end{tabular}

* Girls under I 5 years or over 16 were excluded as the groups were too small for the results to be statistically significant.

†One weight (iso lb) excluded.

Table $\mathrm{r}$ indicates a disproportionate increase in average weights of the girls, and indeed $8 \%$ of them were found to need treatment for their obesity. This school does not appear to be atypical. It has been shown that the natural history of childhood obesity is to continue into adult life (Lloyd, Wolff \& Whelen, I96r) and that serious attempts to treat this condition are therefore essential.

Many Local Authorities and hospitals have clinics devoted to the treatment of childhood obesity but this is almost invariably on an individual basis and consists of dietary advice, sometimes aided by anorectics. Of the reported results, some are extremely encouraging for individual cases, but the failure rate of clinic attendance is high (Massengale, 1965) and this is one of the greatest difficulties in dealing with this condition. Motivation to keep to the prescribed regime is variable and usually has to contend with four 'anti-diet' factors. Of these the home and parental influence is probably of prime importance. Some mothers are extremely helpful and co-operative, often keeping to the diet themselves; but others find it impossible to provide the support necessary. Even when a diet is permissive there may be an increased strain on a family's finances; or a mother may find it impossible to stop giving her child large portions of food, having been indoctrinated in the belief that a plump 'bonny' child is a healthy one. The mothers of underweight children seek advice early but seldom those whose children are too fat (Lorber, 1967 ). Finally, if both mother and daughter are overweight, and the daughter succeeds in her weight reduction while her mother fails, then the prestige of the latter is greatly reduced: there may be an unconscious wish for the mother to preserve the status quo!

The next anti-diet factor is us-the medical profession. Of the girls attending the weight control clinic, $65 \%$ had previously sought medical advice and were either told that their weight would return to normal spontaneously, or else were given diet sheets but inadequate follow-up treatment. While many general practitioners are achieving excellent results and probably greater success than us from their intimate knowledge of the whole family, it must be true that the time necessary to do this is an extra load on an already overtaxed service. For many girls the knowledge that 
their doctors are not interested in their problem has come as a final rejection and made eventual success less likely: this is an important aspect of preventive medicine in which we all have great responsibility.

The third anti-diet factor is the attitude of the girls' own peers, which like the parental one is often ambivalent. While paying lip-service to the need for dieting, they will continue to ply the patient with sweets and biscuits. I think that this is sometimes an unconscious wish to keep the overweight friend in the same state of obesity as a foil for their own slimness.

Finally, of course, is the girls' own attitude to their size and their will-power in adhering to a diet of self-denial. Like Mayer (1965) and unlike Bruch (1940), I have found little psychological disturbance in the girls I have treated, but great difference in their ability to deny themselves the pleasures of particular foods. In many cases this is as difficult as giving up smoking, and substitution of satisfaction is required.

These factors can often be mitigated by treating the obesity on a group basis and thus improving the patient's motivation. The greatest advantage over an individual appointment system is the sense of competition and companionship which develops and the reduction in the sense of isolation from their peers. As the group forms its own identity the girls wish to lose weight not only for their own satisfaction and to earn praise from their parents and doctor, but also to succeed as a member of the group. On a practical basis it is possible to see larger numbers of girls more frequently and, from a dietetic point of view, nutritional fallacies emerge more readily.

A Weight Control Clinic was started in Croydon in June 1965 with this basis, to see if the results would be better than those of conventional treatment. The initial group was composed of ten girls, of whom six were already being treated at school inspection clinics and were not achieving satisfactory weight reduction, and four had heard of the clinic and asked to join. The criteria for membership were liberal. The girls (chosen because I thought I would have greater ease of communication initially with adolescent girls than boys) were between 10 and 16 years old and attended schools in the Croydon area: they were all at least $10 \%$ above their ideal weight estimated for their age and height but the majority were more than $20 \%$ too heavy. They had previously had a gencral medical examination, and urine analyses and blood pressure readings were carried out at the clinic. Permission to attend the clinic was first obtained from the girls' general practitioners and their schools.

Since that initial group three more have been started and, by now, fifty-nine girls have attended this clinic: their results will be given later. The second group, like the first, contained girls who had previously failed to lose weight while attending school inspection clinics, while the third and fourth groups consisted of girls who had received no treatment through the school health service.

The pattern of meetings has been similar for each group. For the initial meeting mothers are asked to attend with the girls; the purpose of the clinic is explained, with a talk on obesity, its causes and possible treatments. Reassurance is given that we do not regard obesity as a sign of gluttony. However, it is stressed that the only way to reduce and control weight is a sensible diet which maintains an adequate protein, vitamin and mineral intake. Diet sheets have been prepared for the clinic 
which are simple to follow, aimed at their age group (Spargo, Heald \& Peckos, ig66) and fit in with the meals of the rest of the family.

Meetings are held fortnightly initially and then at increasingly longer intervals: it was hoped to extend the interval to monthly after 3 months, but this has not always been possible without causing some relapses. Even when the girls' weights have been successfully reduced, they are encouraged to attend for a check up at regular intervals.

At each meeting weights are recorded and at regular intervals the heights and girths also. Individual results are discussed and the group's average gain or loss is calculated. Visual aids are used extensively to reinforce the nutritional education and to maintain interest. These include films, film-strips, use of the Diabetic Association playing cards, and flannelgraphs. The aim is to produce a social rather than medical atmosphere. The results of four groups from June 1965 to June 1967 are shown in Table 2.

\title{
Table 2. Attendances of schoolgirls at Croydon Weight Control Clinic
}

\author{
'l'otal number of girls who have attended clinic \\ 59 \\ Number still attending: \\ Complete reduction to a satisfactory weight* \\ More than two-thirds excess weight lost \\ Less than two-thirds excess weight lost \\ More weight put on \\ Number who have left groups: \\ Satisfactory weight loss achieved 5 \\ Left school to start work 4 \\ Moved from area 2 \\ $\begin{array}{lr}\text { Discovered to be diabetic } & \text { I } \\ \text { Reason for leaving and present weight unknown } & \text { I } 3\end{array}$ \\ Total 25
}

*All these results are not corrected for the girls' increase in height, which was an average of $I_{\frac{1}{2}}$ in.

The total possible number of visits was 698 and the actual total was 472 , which gives a percentage attendance of 67.5 . As this is uncorrected for unavoidable absences due to illness or examinations it is very encouraging.

Comparing the results for the first 6 months of each group (Fig. I) it will be seen that the average losses of groups 3 and 4 are better than those of the first two groups which, I believe, is a reflection of their stronger motivation. In each instance an increase in weight on the graph corresponds with a school holiday.

In order to allow new groups to be formed, existing ones have been amalgamated so that comparing the group results beyond those shown has not been possible. 


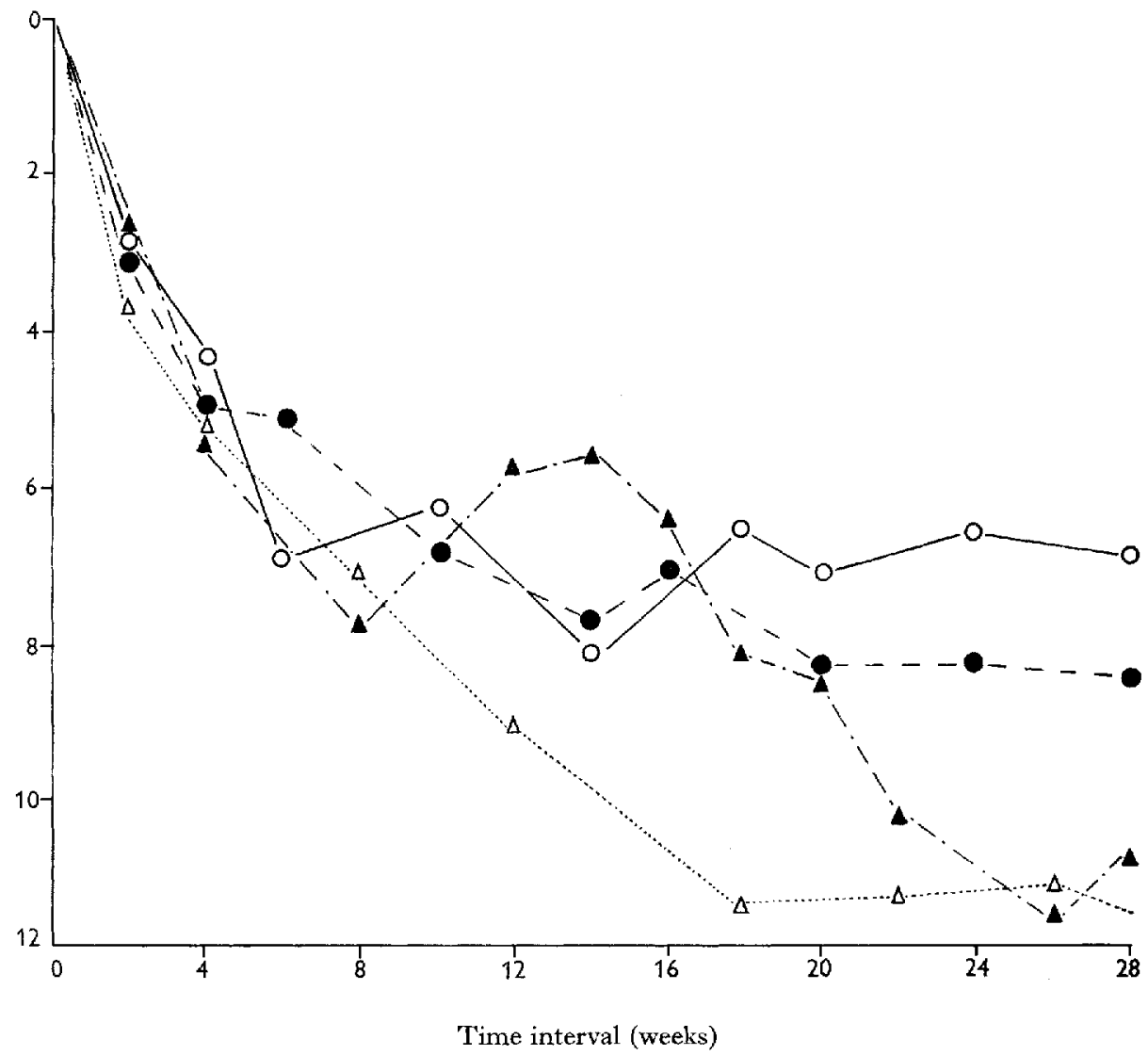

Fig. I. Comparison of mean results for loss of weight by four groups of schoolgirls attending Croydon Weight Control Clinic. $\mathrm{O} \longrightarrow \mathrm{O}$, group $\mathrm{I} ;-\longrightarrow \longrightarrow$, group $2 ; \triangle \ldots \ldots \ldots \Delta$, group $3 ; \mathbf{A},-\mathbf{\Lambda}$ group 4 .

It soon became apparent that the numbers of girls needing treatment were great and so we have formed groups meeting in the schools themselves. For these to be possible, three conditions must be met:

(I) There must be a sufficient number of overweight girls to justify the group.

(2) Regular visits from the doctor at a time that does not interfere with school routine are essential.

(3) Most important the heads of the schools must be enthusiastic and encouraging about the idea and a member of the staff must accept responsibility for the weighing and supervision of the groups.

These criteria are met fully in the two schools whose results I am going to quote and I am extremely grateful to the headmistresses and staffs who have helped me in this venture. In both schools my visits were rather haphazard at first and the results reflected this: this term (spring term, r 967 ) however I have visited each school once fortnightly and eaten a packed lunch with the groups. I can check that the lunches the girls have brought are nutritionally and calorifically sound, and discuss their 27 (1) 3 
weight losses (or gains!) in an informal way. This does not interfere with school work or extracurricular activities. The enthusiasm of both groups is great and they have produced their own magazines. The results this term are shown in Table 3 .

Table 3. Weight changes of schoolgirls attending a weight control clinic held in two schools

School A:

\begin{tabular}{lrl} 
No. who lost weight & I4 & (maximum I5 lb) \\
No. who gained weight & 5 & (maximum $3 \frac{1}{2} \mathrm{lb}$ ) \\
Weight stationary & 3 & \\
\multicolumn{1}{c}{ Total } & $2 \mathrm{I}$ &
\end{tabular}

School B:

No. who last weight II (maximum Io lb)

No. who gained weight 3 (maximum $3 \frac{1}{2} 1 \mathrm{~b}$ )

Weight stationary 5

Total 19

Although not outstanding, these results are promising, especially as several girls had spectacular weight losses in the groups last term; and I feel this is a type of treatment which warrants further investigation.

The aim of the Public Health Service must always be preventive rather than therapeutic, and it is our sincere wish that we may be able to prevent adolescent obesity by better nutritional education of mothers and the early detection of children at risk in this condition. Until this situation occurs, however, we will have a large population of overweight schoolchildren who, untreated, will become overweight adults with all the accompanying risks to health and happiness. The School Health Service has a particular responsibility for these children, and the methods I have outlined are at least one approach to their treatment.

\section{REFERENCES}

Bruch, H. (1940). Am. F. Dis. Child. 59, 739.

Lloyd, J. K., Wolff, O. H. \& Whelen, W. S. (196r). Br. med. Y. ii, 145.

Lorber, J. (1967). Medical Nezus Magazine, January, p. I5.

Massengale, O. N. $(1,65)$. Clin. Pediat. 4, 649.

Mayer, J. (1965). Med. Clins N. Am. 49, no. 2, p. 425.

Scott, J. A. (1955). Report on the Heights and Weights of School Pupils in the County of London in $\mathbf{1 9 5 4}$, London County Council Publication 3885 .

Spargo, J. A., Heald, F. \& Peckos, P. S. (rg66). Nutrition Today, N.Y. 1, no. 4, p. 2. 